Short Communication

\title{
Effect of pruning and pollarding on shoot development in bakphul (Sesbania grandiflora L.)
}

\author{
M.S. Islam, M.A. Hossain and M.A. Mondol \\ Department of Agroforestry, Bangladesh Agricultural University, Mymensigh-2202, Bangladesh
}

\begin{abstract}
An experiment was carried out in a roadside agroforestry system established along farm roadsides of Bangladesh Agricultural University, Mymensingh, to investigate the effects of pruning and pollarding on shoot development in Sesbania grandiflora L. Six treatment combinations with the stock plants studied during the period from August to September, 2007. The results revealed that the different pruning and pollarding levels had significant variations on the parameters studied at different days after pruning (DAP). Among the treatments the pollarded shoot tip with lower and upper branch pruning produced the highest number of new branches (572) followed by the treatment of intact shoot tip with lower and upper branch pruning with 454 new branches at 60 DAP. The new branches produced from pruning and pollarding treatments attained its maximum length within a very short time. Maximum branch length $(24.66 \mathrm{~cm})$ was observed in the treatments of pollarded shoot tip with lower and upper branch pruned off condition followed by the treatment of intact shoot tip with lower and upper branch pruned off condition which attained $17.67 \mathrm{~cm}$ of length at 21 DAP. Again the pollarded shoot tip with lower and upper branch pruning produced 1127 number of leaves followed by the treatment of intact shoot tip with lower and upper branch pruning produced 999 leaves at 60 DAP. The results of this study suggest that the severely pruned plant (both lower and upper branch pruned along with pollarded shoot tip) not only produced huge amount of shoot biomasses but also enhance the development of new shoots within a very short period.
\end{abstract}

Keywords: Sesbania grandiflora L., Agroforestry, Pruning and Pollarding.

\section{Introduction}

Sesbania grandiflora L. is a fast growing tropical leguminous tree that has multiple economic uses. The useful characteristics of this species include rapid growth, high biomass production, easily propagation from seed, abundant nodulation and potential as nitrogen fixer. Therefore it has a great potentiality in an agrobased country like Bangladesh. The forest resources of the country are being destroyed at an alarming rate. Hence some alternate approaches like agroforestry system should be followed to meet the land crisis situation. Agroforestry is recognized worldwide as the best productive systems from which the rural poor people can meet their 5 F's demand i.e. food, fuel, fodder, furniture and fund. The increase in fodder and biomass production through the management practices of agroforestry system is such a desirable way that should be largely practiced in this country. Pruning and pollarding are the most common practices which should be used in cropland agroforestry as well as in some special cases of utility land, homestead and well bound agroforestry systems. Pruning of shoots is necessary in all stages of growth in order to have desired trunk and canopy structures of the MPTs. The straight trunk should be allowed to grow until it attains a height of about $2.5 \mathrm{~m}$. Unusually long branches and upper axis may also be cut off, if necessary, to attain desired canopy structure. (Hossain, 1994). On the other hand, Pollarding is the use of proper pruning cuts to make tree crowns smaller and to permanently keep them that way. Thus, Sesbania grandiflora can be pruned, lopped or pollarded for shoot development, forage production and green mannuring purposes. Therefore, the present study was undertaken with a view to determine shoot development especially leaf forage in Sesbania grandiflora L. 


\section{Materials and Methods}

The present experiment was carried out in the experimental plots under a Roadside Agroforestry Project established along farm road sides of Bangladesh Agricultural University, Mymensingh during the period from August to September, 2007. The experimental area is located (AEZ-9) at $24^{\circ} 75^{\prime} \mathrm{N}$ latitude and $90^{\circ} 50^{\prime} \mathrm{E}$ longitude at an $18 \mathrm{~m}$ above the sea level (UNDP and FAO, 1988). The experiment was conducted in a Randomized Complete Block Design (RCBD) with three replications. There were six treatments and three blocks in the experiment. In this study one and half years old Sesbania grandiflora $L$. plants were used as a plant material. There were two factors of the experiment viz. A. Shoot tip conditions which include- a). shoot tip intact b). shoot tip pollarded and B. Branch pruning levels which includec). no pruning d). only lower branches pruned off (up to $1.75 \mathrm{~m}$ height) and e). Lower + upper branches pruned off at $50 \%$ length. Hence, the treatments were $T_{1}=$ control, $T_{2}=$ intact tip with lower branches pruned off up to $1.75 \mathrm{~m}$ height, $\mathrm{T}_{3}=$ intact tip with lower + upper branches pruned off at $50 \%$ length, $T_{4}=$ shoot tip pollarded with no branch pruning, $T_{5}=$ shoot tip pollarded with lower branches pruned off, $\mathrm{T}_{6}=$ pollarded shoot tip with both lower + upper branches pruned off at $50 \%$ length. The parameters were the number of new branches, length of new branches and total numbers of leaves in new branches as an indicator of leaf forage production of the pruned plants at different DAP in Sesbania grandiflora. All the parameters were studied and data were recorded. The data for each of the parameters were analyzed to find out variations resulting from experimental treatments. The mean results were compared by Least Significant Difference (LSD) Test (Gomez and Gomez, 1984)

\section{Results and Discussion}

At day 60 the new branch number was 464 in pollarded shoot tip and 300 in intact shoot tip. Thus the stocks with pollarded shoot tip produced the highest number of new branches (Table 1). Maximum number of branches (513) was observed in severe pruned stocks i.e. lower + upper branch pruned level at 60 DAP and minimum branch number (289) was recorded in no pruning condition at the same DAP (Table 2). Maximum number (572) of branches was observed in treatment of pollarded shoot tip with lower + upper branch pruned off condition at 60 DAP and minimum branch number (179) was recorded in the treatment of intact tip with no branch pruning level at the same DAP. (Table.3)

Table 1. Effect of shoot tip conditions on number of new branches at different DAPs in Sesbania grandiflora

\begin{tabular}{|l|c|c|c|c|c|c|c|}
\hline \multirow{2}{*}{ Shoot tip condition (A) } & \multicolumn{7}{|c|}{ Days after pruning/pollarding (DAP) } \\
\cline { 2 - 8 } & 7 DAP & 14 DAP & 21 DAP & 28 DAP & 35 DAP & 42 DAP & 60 DAP \\
\hline Shoot tip intact & 100 & 154 & 203 & 246 & 263 & 281 & 300 \\
\hline Shoot tip pollarded & 191 & 269 & 306 & 367 & 380 & 416 & 464 \\
\hline LSD (P $\geq 0.05)$ & 16.35 & 18.43 & 15.26 & 20.13 & 16.75 & 18.02 & 14.28 \\
\hline
\end{tabular}

Table 2. Effect of branch pruning levels on number of new branches at different DAPs in Sesbania grandiflora

\begin{tabular}{|l|c|c|c|c|c|c|c|}
\hline \multirow{2}{*}{ Branch Pruning levels (B) } & \multicolumn{7}{|c|}{ Days after pruning/pollarding (DAP) } \\
\cline { 2 - 9 } & 7 DAP & 14 DAP & 21 DAP & 28 DAP & 35 DAP & 42 DAP & 60 DAP \\
\hline No pruning & 86 & 139 & 161 & 219 & 232 & 259 & 289 \\
\hline Lower branches pruning & 120 & 177 & 223 & 269 & 285 & 313 & 344 \\
\hline Lower + Upper branches pruning & 230 & 319 & 381 & 433 & 449 & 473 & 513 \\
\hline LSD (P $\geq 0.05)$ & 17.44 & 16.75 & 19.66 & 14.33 & 13.49 & 21.21 & 11.22 \\
\hline
\end{tabular}


Table 3. Interaction effect of shoot tip condition and branch pruning level on number of new branches at different DAP in Sesbania grandiflora

\begin{tabular}{|c|c|c|c|c|c|c|c|}
\hline Treatment combination & \multicolumn{7}{|c|}{ Days after pruning/pollarding (DAP) } \\
\cline { 2 - 8 }$(\mathrm{A} \times \mathrm{B})$ & 7 DAP & 14 DAP & 21 DAP & 28 DAP & 35 DAP & 42 DAP & 60 DAP \\
\hline $\mathrm{T}_{1}$ & 29 & 69 & 105 & 142 & 155 & 166 & 179 \\
\hline $\mathrm{T}_{2}$ & 73 & 106 & 161 & 200 & 220 & 245 & 267 \\
\hline $\mathrm{T}_{3}$ & 198 & 287 & 344 & 396 & 415 & 432 & 454 \\
\hline $\mathrm{T}_{4}$ & 142 & 209 & 216 & 295 & 309 & 351 & 398 \\
\hline $\mathrm{T}_{5}$ & 168 & 247 & 286 & 337 & 350 & 382 & 422 \\
\hline $\mathrm{T}_{6}$ & 262 & 350 & 418 & 469 & 483 & 514 & 572 \\
\hline $\mathrm{LSD}(\mathrm{P} \geq 0.05)$ & 24.67 & 23.69 & 27.80 & 20.27 & 19.08 & 29.99 & 15.86 \\
\hline $\mathrm{CV} \%$ & 9.32 & 6.15 & 6.00 & 3.63 & 3.26 & 4.73 & 2.28 \\
\hline
\end{tabular}

The length of branches was observed to be very slow increase $(4.311 \mathrm{~cm})$ in intact tip and more or less similar $(6.711 \mathrm{~cm})$ in pollarded tip at 7 DAP. However, it slowly increased by 14 DAP, followed by more or less rapid increase subsequently. The maximum length was $64.00 \mathrm{~cm}$ in pollarded shoot tip and $44.88 \mathrm{~cm}$ in intact shoot tip at 60 DAP (Table 4). The highest length $(72.33 \mathrm{~cm})$ were observed in more pruned level i.e. both lower + upper branches pruned off at $50 \%$ of branch length and the lowest length $(42.50 \mathrm{~cm})$ was recorded in no pruning condition which were statistically similar to lower branch pruned off level which results $(48.500 \mathrm{~cm})$ length at 60 DAP $($ Table 5$)$. The highest length $(24.66 \mathrm{~cm})$ was observed in treatment of pollarded shoot tip with lower + upper branch pruned off condition at 21 DAP while the lowest length $(11.33 \mathrm{~cm})$ was found in the treatment of control with intact tip + no branch pruning condition. (Table 6)

Table 4. Effect of shoot tip conditions on length $(\mathrm{cm})$ of new branches at different DAPs in Sesbania grandiflora

\begin{tabular}{|l|c|c|c|c|c|c|c|}
\hline \multirow{2}{*}{ Shoot tip condition (A) } & \multicolumn{7}{|c|}{ Days after pruning/pollarding (DAP) } \\
\cline { 2 - 9 } & 7 DAP & 14 DAP & 21 DAP & 28 DAP & 35 DAP & 42 DAP & 60 DAP \\
\hline Shoot tip intact & 4.31 & 7.55 & 14.11 & 20.78 & 28.11 & 40.33 & 44.88 \\
\hline Shoot tip pollarded & 6.71 & 10.50 & 18.55 & 27.71 & 36.33 & 54.22 & 64 \\
\hline LSD (P $\geq 0.05)$ & 0.76 & 0.54 & 1.50 & 1.86 & 2.11 & 2.04 & 5.06 \\
\hline
\end{tabular}

Table 5. Effect of branch pruning levels on length $(\mathrm{cm})$ of new branches at different DAPs in Sesbania grandiflora

\begin{tabular}{|l|c|c|c|c|c|c|c|}
\hline \multirow{2}{*}{ Branch Pruning levels (B) } & \multicolumn{7}{|c|}{ Days after pruning/pollarding (DAP) } \\
\cline { 2 - 8 } & $7 \mathrm{DAP}$ & $14 \mathrm{DAP}$ & 21 DAP & 28 DAP & $35 \mathrm{DAP}$ & $42 \mathrm{DAP}$ & $60 \mathrm{DAP}$ \\
\hline No pruning & 4.40 & 7.32 & 13.33 & 19.50 & 27.33 & 37.67 & 42.50 \\
\hline Lower branches pruning & 4.81 & 8.02 & 14.33 & 22.17 & 29.83 & 43.50 & 48.50 \\
\hline Lower + Upper branches pruning & 7.32 & 11.75 & 21.17 & 31.07 & 39.50 & 60.67 & 72.33 \\
\hline LSD $(\mathrm{P} \geq 0.05)$ & 0.59 & 0.58 & 1.32 & 2.18 & 2.65 & 2.09 & 6.90 \\
\hline
\end{tabular}

Leaf number was observed to be very low (166) in intact tip and (353) in pollarded tip at 7 DAP. The maximum leaf number was 976 in pollarded shoot tip and 634 in intact shoot tip at 60 DAP. (Table 7) The highest leaf number (1063) was observed in severe pruning level i.e. both lower + upper branches pruned off at $50 \%$ of branch length and the lowest leaf number (652) was recorded in no pruning level at 60 DAP (Table 8). The highest leaf number (1127) was observed in treatment of pollarded shoot tip with lower + upper branch pruning level at 60 DAP and the lowest (447) was recorded in treatment of control which was similar (454) to treatment of intact tip + lower branch pruned off condition at same DAP. (Table 9) 
Table 6. Interaction effect of shoot tip condition and branch pruning levels on the length $(\mathrm{cm})$ of new branches at different DAP in Sesbania grandiflora

\begin{tabular}{|c|c|c|c|c|c|c|c|}
\hline $\begin{array}{c}\text { Treatment combination } \\
(\mathrm{A} \times \mathrm{B})\end{array}$ & \multicolumn{7}{|c|}{ Days after pruning/pollarding (DAP) } \\
\cline { 2 - 9 } & 7 DAP & 14 DAP & 21 DAP & 28 DAP & 35 DAP & 42 DAP & 60 DAP \\
\hline $\mathrm{T}_{1}$ & 2.90 & 6.06 & 11.33 & 15.66 & 22.33 & 30.33 & 32.00 \\
\hline $\mathrm{T}_{2}$ & 3.40 & 6.76 & 13.00 & 19.66 & 25.33 & 35.66 & 39.33 \\
\hline $\mathrm{T}_{3}$ & 6.63 & 9.83 & 17.66 & 27.00 & 36.66 & 55.00 & 63.33 \\
\hline $\mathrm{T}_{4}$ & 5.90 & 8.56 & 15.33 & 23.33 & 32.33 & 45.00 & 53.00 \\
\hline $\mathrm{T}_{5}$ & 6.23 & 9.26 & 15.66 & 24.66 & 34.33 & 51.33 & 57.66 \\
\hline $\mathrm{T}_{6}$ & 8.00 & 13.66 & 24.66 & 35.13 & 42.33 & 66.33 & 81.33 \\
\hline $\mathrm{LSD}(\mathrm{P} \geq 0.05)$ & 0.84 & 0.83 & 1.87 & $\mathrm{NS}$ & $\mathrm{NS}$ & $\mathrm{NS}$ & $\mathrm{NS}$ \\
\hline $\mathrm{CV} \%$ & 8.46 & 5.06 & 6.31 & 7.00 & 6.04 & 3.45 & 9.86 \\
\hline
\end{tabular}

Table 7. Effect of shoot tip condition on the number of leaves in new branches at different DAPs in Sesbania grandiflora

\begin{tabular}{|c|c|c|c|c|c|c|c|}
\hline Shoot tip condition & \multicolumn{7}{|c|}{ Days after pruning/pollarding (DAP) } \\
\cline { 2 - 8 }$(\mathrm{A})$ & 7 DAP & 14 DAP & 21 DAP & 28 DAP & 35 DAP & 42 DAP & 60 DAP \\
\hline Shoot tip intact & 166 & 227 & 363 & 440 & 489 & 525 & 634 \\
\hline Shoot tip pollarded & 353 & 472 & 607 & 721 & 765 & 820 & 976 \\
\hline LSD (P $\geq 0.05)$ & 24.54 & 22.69 & 24.82 & 27.04 & 22.03 & 31.06 & 37.80 \\
\hline
\end{tabular}

Table 8. Effect of branch pruning levels on number of leaves in new branches at different DAPs in Sesbania grandiflora

\begin{tabular}{|l|c|c|c|c|c|c|c|}
\hline \multirow{2}{*}{ Branch Pruning levels (B) } & \multicolumn{7}{|c|}{ Days after pruning/pollarding (DAP) } \\
\cline { 2 - 9 } & 7 DAP & 14 DAP & 21 DAP & 28 DAP & 35 DAP & 42 DAP & 60 DAP \\
\hline No pruning & 179 & 225 & 370 & 469 & 527 & 563 & 652 \\
\hline Lower branches pruning & 205 & 266 & 438 & 508 & 545 & 582 & 699 \\
\hline $\begin{array}{l}\text { Lower + Upper branches } \\
\text { pruning }\end{array}$ & 394 & 559 & 647 & 766 & 810 & 873 & 1063 \\
\hline LSD (P $\geq 0.05)$ & 25.55 & 30.63 & 20.83 & 26.99 & 21.24 & 38.29 & 46.14 \\
\hline
\end{tabular}

Table 9. Interaction effect of shoot tip condition and branch pruning levels on the number of leaves in new branches at different DAP in Sesbania grandiflora

\begin{tabular}{|c|c|c|c|c|c|c|c|}
\hline \multirow{2}{*}{$\begin{array}{c}\text { Treatment } \\
\text { combination } \\
(\mathrm{A} \times \mathrm{B})\end{array}$} & \multicolumn{7}{|c|}{ Days after pruning/pollarding (DAP) } \\
\cline { 2 - 8 } & 7 DAP & 14 DAP & 21 DAP & 28 DAP & 35 DAP & 42 DAP & 60 DAP \\
\hline $\mathrm{T}_{1}$ & 66 & 94 & 188 & 255 & 340 & 386 & 447 \\
\hline $\mathrm{T}_{2}$ & 91 & 137 & 306 & 330 & 348 & 371 & 454 \\
\hline $\mathrm{T}_{3}$ & 341 & 451 & 595 & 733 & 779 & 819 & 999 \\
\hline $\mathrm{T}_{4}$ & 292 & 355 & 553 & 678 & 713 & 740 & 857 \\
\hline $\mathrm{T}_{5}$ & 318 & 395 & 569 & 686 & 741 & 793 & 943 \\
\hline $\mathrm{T}_{6}$ & 447 & 667 & 699 & 799 & 841 & 926 & 1127 \\
\hline $\mathrm{LSD}(\mathrm{P} \geq 0.05)$ & 36.14 & $\mathrm{NS}$ & 29.46 & 38.17 & 30.04 & 54.16 & 65.25 \\
\hline $\mathrm{CV} \%$ & 7.66 & 6.81 & 3.34 & 3.62 & 2.63 & 4.42 & 4.46 \\
\hline
\end{tabular}

The results presented in this study are in good conformity with other researchers. In this study it was observed that severe pruning/pollarding condition i.e. pollarded shoot tip with lower and upper branch pruning levels always produced higher number of buds, branches and leaves followed by the treatment of intact tip with lower and upper branch pruning level. 
According to Bisla et al. (1990) hard pruning results significant effect on higher number of secondary and tertiary shoots and the largest leaf area. The results of the present study are similar to the findings of Bisht et al. (1998) who observed that pollarding G. optiva at $2 \mathrm{~m}$ height but leaving the main shoot intact to produce maximum fuel and fodder. Tipu et al. (2006) observed that the stocks with higher pruning height $(150 \mathrm{~cm})$ always produced higher number of branches as well as leaves than those with lower pruning heights $(100 \mathrm{~cm})$. According to Hossain (2007) the pruning of branches and pollarding of upper levels of Neem, Jatropha and Bakphul markedly enhanced shoot regeneration resulting the plants into stout, good looking and uniform in appearance, as well as, higher production of shoot biomass compared to control plants. After pruning and pollarding the rapid growth and development of young shoots also indicate that this practice will be commercially helpful to the farmers of Bangladesh for forage, fuel and green manure production.

\section{References}

Bisht, J.K., Chandra, S., Jagpal Singh and Singh, R.D. 1998. Effect of cutting methods on the forage and fuel yield of bhimal (Grewia optiva) in mid hills of NW. Himalayas. Range Manage. Agroforest., 19(2): 206-207.

Bisla, S.S., Dhiman, B.K. and Daulta, B.S. 1990. Effect of pruning and spacing on vegetative growth of ber (Zizyphus mauritiana Lam). Haryana. J. Hort. Sci., 19(3-9): 256-262.

Gomez, K.A. and Gomez, A.A. 1984. Statistical procedure for Agricultural Research. John Wiley and Sons. Inc. New York, pp. 20-206.

Hossain, M.A. 1994. Pruning, training and management of woody plants. In: M.A. Haque. Village and farm forestry in Bangladesh. Joint Pub. Bangladesh Agric. Univ., Mymensingh and Swiss Dev. Coop., Dhaka.

Hossain, M.A. 2006. Development of models for sustainable multistoried production systems in roadside and farmland Agroforestry. Bangladesh Agric. Univ. Res. Prog., 17: 37-38.

Hossain, M.A. 2007. Development of sustainable multistoried production systems in roadside, farmland and homesteads by novel plantation and agroforestry management technologies. Final Rep. BAU Res. Prog., Mymensingh.

Tipu, S.U., Hosain, K.L., Islam, M.O. and Hossain, M.A. 2006. Effect of pruning height and shoot biomass yield of Leucaena leucocephala. Asian J. Plant Sci. 5(6): 1043-1046.

UNDP (United Nations Development Program) and FAO (Food and Agricultural Organijation). 1988. Land Resource Appraisal of Bangladesh for Agricultural Development. Rep. 2. Agroecol. Reg. Bangladesh. pp. 212-221. 